\title{
DECIDIR, ARGUMENTAR Y ENGROSAR: EL CASO MARTÍN DEL CAMPO*
}

\author{
Roberto Lara Chagoyán*** \\ roberto.larac@gmail.com
}

RESUMEN. El proceso de decisión en la Suprema Corte mexicana consiste en discutir un proyecto de resolución, llevar a cabo una deliberación y tomar una votación. Posteriormente, se encarga a uno de los ministros la elaboración de un documento que, en teoría, debe contener los argumentos que fundamentan el acuerdo alcanzado en la deliberación. Sin embargo, algunas veces el documento no coincide con lo acordado. El propósito de este trabajo es analizar en profundidad uno de estos casos y sus implicaciones en el sistema jurídico mexicano. También se aborda el tema de la falta de un pronunciamiento sobre uno de los temas centrales de la decisión: la obligatoriedad de los informes de la Comisión Interamericana de Derechos Humanos.

Palabras clave: tortura, decisión, formalismo, obligatoriedad, deber, obligación, Informe de Fondo, Comisión Interamericana de Derechos Humanos, reconocimiento de inocencia, juicio de amparo.

\section{Voting, Arguing and Drafting: Producing a Judgment to the Martín del Campo Case}

ABSTRACT. The decision-making in the Mexican Supreme Court consists of a process that encompasses the distribution of a draft judgment, deliberation and voting. Once justices reached an agreement, one of them becomes in charge of preparing a final judgement that, in theory, must resemble such agreement. In practice, however, some judgments do not reflect neither the arguments nor the agreement made by justices. The purpose of this article is to analyze in depth one of this cases in order to provide some remarks about the implications of the Court's decision-making process for Mexico's legal system. Also, the paper debates about one of the case's major topics: the lack of providing an analysis regarding the obligatory status of the Inter-American Commission on Human Rights' Reports on merits.

Keywords: torture, decision-making, compulsoriness, Inter-American Human Rights Commission, reports on cases, amparo.

* Fecha de recepción: 4 de mayo de 2017. Fecha de aceptación: 30 de mayo de 2017.

** Director General del Centro de Estudios Constitucionales de la Suprema Corte de Justicia de la Nación México.

Agradezco a Camilo SaAvedra, Alejandra Martínez Verástegui, Diana Beatriz GonZÁlez Carballo, Karla Quintana Osuna, Fernanda Aguilar Cortés y Grizel Robles CÁRDEnAS, sus valiosos comentarios a las diferentes versiones de este trabajo. 


\section{INTRODUCCIÓN}

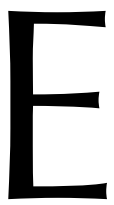

118 de marzo de 2015, la Primera Sala de la Suprema Corte de Justicia de la Nación de México (SCJN) decidió ordenar la libertad inmediata de Alfonso Martín del Campo Dodd, quien había permanecido en prisión durante veintitrés años por un doble homicidio, mediante una confesión obtenida por tortura, como única prueba (amparo en revisión 631/2013). En esa sesión, se determinó que uno de los ministros (magistrados) se hiciera cargo del «engrose», el cual se publicó hasta el 9 de febrero de 2016, es decir, casi once meses después. En la Corte mexicana llamamos «engrose» al escrito final de una sentencia que se emite luego de haberse decidido el caso en una sesión pública mediante la deliberación correspondiente a partir de un proyecto inicial a cargo del ministro ponente ${ }^{1}$. El proyecto original y el engrose pocas veces coinciden, y los ministros que suscriben tales documentos tampoco suelen ser los mismos. Ello no tendría nada de particular si entre estas tres acciones (proyectar, decidir y engrosar) existiera una línea coherente en la que los posibles cambios reflejaran los avances en la decisión.

En este caso en particular, se discutió un primer proyecto a cargo del ministro José Ramón Cossío Díaz el 2 de julio de 2014, en el cual se proponía conceder el amparo «liso y llano» ${ }^{2}$ al quejoso, con lo cual se habría ordenado su libertad inmediata; sin embargo, el proyecto fue desechado, esencialmente, porque la mayoría de los ministros consideró que no convenía «comprometer el criterio ${ }^{3}$ de la Sala con relación a la obligatoriedad de los Informes de la Comisión Interamericana de Derechos Humanos (CIDH), en los cuales se tenía por probada la tortura. Conviene aclarar que la obligatoriedad de esos informes era uno de los temas planteados en el recurso de revisión que la Corte resolvió, esto es, se trataba de un tema cuya resolución no era optativa sino obligatoria.

Siete meses después, el 18 de marzo de 2015, se presentó un segundo proyecto de resolución a cargo del ministro Jorge Mario Pardo Rebolledo a quien, por cuestión de turno, le había correspondido tal encomienda. Esta vez el proyecto no tomó en cuenta los informes de la CIDH y propuso conceder el amparo «para efectos», es decir, propuso emitir una orden al tribunal de segunda instancia (autoridad responsable) para que analizara algunas pruebas ofrecidas por el quejoso. No obstante lo anterior, la propuesta no convenció al resto de los integrantes de la Sala por razones de las que luego me ocuparé. Lo cierto es que consideraron que con esa resolución era improbable que el quejoso obtuviera su libertad.

El dilema continuaba en el aire. Sin embargo, habiendo analizado pormenorizadamente todo el expediente de reconocimiento de inocencia y también la causa penal, la mayoría de los ministros quedó convencida de que no había duda alguna de que Alfonso Martín del Campo había sido torturado, y que el amparo debía concederse de

${ }^{1} \mathrm{El}$ engrose, por lo regular, es el proyecto inicial modificado que acoge las sugerencias surgidas en la discusión que se lleva a cabo el día de la sesión; sin embargo, existen casos en los que, prácticamente, se elabora un nuevo documento a partir de lo acordado por los ministros.

2 «Liso y llano» en la jerga judicial significa que el amparo se concede de manera inmediata o directa, sin que tenga que regresar el expediente a la autoridad responsable para que dicte otra resolución en la que cumpla con lo ordenado por el tribunal de amparo. Lo contrario es el «amparo para efectos».

3 Esta frase se utiliza normalmente para defender una postura silenciosa de la Suprema Corte ante un determinado problema. 
manera lisa y llana, es decir, como lo había propuesto el ministro José Ramón Cossío Díaz en el primer proyecto, pero sin atender los informes de la CIDH. De este modo, se determinó que el ministro Alfredo Gutiérrez Ortiz Mena quedara como encargado de la redacción del engrose y que se ordenara la inmediata libertad de Alfonso Martín del Campo Dodd. Este acuerdo permitió que el caso fuera «decidido» ese 18 de marzo de 2015. Pero lo que la mayoría no acordó fue qué vía o vías argumentativas debían seguirse para alcanzar esa decisión.

En este trabajo haré una crítica al modelo de toma de decisiones en México a partir de este caso. Busco responder a la pregunta sobre cuál es el valor de un proyecto de resolución a cargo de una de las ponencias y cuál el de los llamados «engroses». Desde mi punto de vista, si la Corte decide un caso mediante la deliberación sin tomar en cuenta necesariamente el proyecto y, después, elabora un engrose sin tomar en cuenta necesariamente la decisión, entonces tenemos un problema.

Por lo demás, el caso elegido es uno de los más controvertidos en los últimos años en México, puesto que versa sobre tortura. La tortura es un fenómeno cultural asociado a la administración y procuración de justicia que, por desgracia, desde hace mucho tiempo forma parte del quehacer cotidiano de las autoridades dedicadas a la investigación de los delitos y a la seguridad pública. Pero este caso en particular, además, tiene aristas que lo distinguen de otros casos de tortura por varias razones: 1) porque se trata de un asunto relacionado con el homicidio de una pareja, en su propio domicilio, con utensilios de cocina y que, aparentemente, lo había perpetrado un miembro de la familia: Alfonso Martín del Campo Dodd, hermano de la mujer asesinada (así fue difundido por la autoridad y por los medios de comunicación); 2) porque —-como ya adelanté- la única prueba que se utilizó para fincar su responsabilidad penal fue una confesión (así lo aceptó el tribunal de segunda instancia); 3) porque esa confesión fue obtenida - como se comprobó después- mediante el empleo de la tortura; 4) porque, una vez que el caso fue cerrado en México por haberse agotado las instancias jurisdiccionales internas, incluyendo el amparo, se abrió un litigio internacional que, por circunstancias de competencia temporal, no pudo ser resuelto por la Corte Interamericana de Derechos Humanos (CorteIDH) - los hechos ocurrieron en 1992 y México reconoció la competencia contenciosa de ese organismo hasta 1998- aunque fue atendido con importantes resultados en la $\mathrm{CIDH}$; 5) porque el caso despertó el interés en el ámbito legislativo del entonces Distrito Federal y del Senado de la República, lo que se tradujo en importantes reformas legales y pronunciamientos políticos; 6) porque el caso, el litigio y la resolución final estimularon el interés en la academia y la sociedad en general; 7) porque el caso ha servido como acicate para despertar la polémica en torno al binomio tortura-impunidad; y 8) porque, a la hora de resolver de manera definitiva el problema, la SCJN evadió de forma deliberada una de las cuestiones centrales: la pregunta por la obligatoriedad de los informes de la CIDH. Este último punto es particularmente delicado, pues a partir de la reforma constitucional en materia de derechos humanos de 2011, el Constituyente Permanente estableció un mandato según el cual ninguna autoridad podrá desconocer el papel de los instrumentos internacionales en la materia en la resolución de los conflictos sociales y menos que nadie, la Suprema Corte. ¿Qué razones están detrás de esta omisión? ¿Qué sucede en el seno de un Tribunal Constitucional cuando va a resolver un asunto de este tipo? 
Procederé de la siguiente forma: en primer lugar, narraré la historia del caso (I); posteriormente, distinguiré entre la decisión y el engrose (II); más adelante exploraré las razones «políticas» que, a mi juicio, están detrás del silencio de la Corte con relación a la obligatoriedad de los informes de la CIDH (III); enseguida, diré por qué y de qué manera pudieron haberse tomado en cuenta tales informes (IV); y finalmente, presentaré algunas conclusiones $(\mathrm{V})$.

\section{LOS HECHOS DEL CASO Y LA SECUELA PROCESAL}

Existen dos versiones de los hechos, como suele ocurrir en todos los asuntos criminales. La del Ministerio Público es la siguiente: Alfonso Martín del Campo Dodd confesó que asesinó a su hermana y a su cuñado de «forma despiadada», utilizando guantes de plástico y utensilios de cocina, y que perpetró el ataque mientras estaban dormidos. El ataque habría derivado de una discusión sostenida horas antes entre las víctimas y el victimario por cuestiones de dinero. En la confesión se detalla que Alfonso Martín del Campo huyó a bordo del coche de su cuñado, que se dirigió hacia Cuernavaca pero que tuvo un accidente en la carretera y regresó a la ciudad de México, donde acudió a la oficina de la entonces Policía Federal de Caminos para informar falsamente que había sido secuestrado en su domicilio por dos personas, y que necesitaba comunicarse con su familia para asegurarse que se encontraban a salvo.

La segunda versión es la de Alfonso Martín del Campo. Él sostuvo que la confesión que firmó, y que fue la única prueba en la que se basó todo el juicio, fue arrancada mediante actos de tortura a cargo de oficiales de la policía judicial. Aseguró que lo que en realidad sucedió el 29 de mayo de 1992 fue lo siguiente: aproximadamente a las 22:30 horas, llegó a su domicilio y se dirigió a su habitación donde, poco tiempo después, se quedó dormido sin percatarse de la hora a la que llegaron sus familiares. Horas después despertó al oír los gritos de su hermana que lo llamaba, por lo que de inmediato se levantó de la cama y se dirigió hacia donde ella se encontraba. Al abrir la puerta de su habitación, se percató de la presencia de un sujeto que tenía la cabeza cubierta por una media quien, al verlo, se lanzó hacia él, comenzó a golpearlo y lo obligó violentamente a recostarse sobre su cama. Una segunda persona entró a su habitación portando un cuchillo en la mano derecha y, entre los dos, continuaron golpeándolo. Momentos después, lo amordazaron con un pedazo de toalla, lo subieron al maletero del automóvil de su cuñado y condujeron por varios minutos. De pronto, escuchó un fuerte golpe y sintió que el vehículo se había detenido. Una vez que se las arregló para abrir la cajuela del coche y, después de pedir auxilio sin resultado alguno, caminó por la carretera hasta que logró encontrar un camión que lo llevó hasta la caseta de cobro, donde llamó a la policía para decirles que lo habían secuestrado. Afirmó, finalmente, que durante la diligencia de reconstrucción de hechos, los agentes de la entonces Policía Judicial lo corrigieron todo el tiempo y, mediante amenazas, lo obligaron a decir lo que ellos quisieron.

La versión que se tomó en cuenta en el proceso judicial fue la de la autoridad. Así, en la sentencia de primera instancia, dictada el 28 de mayo de 1993, el juez determinó que Alfonso Martín del Campo Dodd era responsable del doble homicidio calificado, 
por lo que le impuso una pena de cincuenta años de prisión ${ }^{4}$. El 17 de agosto de 1993, la segunda instancia confirmó la decisión ${ }^{5}$.

En febrero de 1994, luego de una denuncia a cargo de la defensa del sentenciado, la Procuraduría de Justicia del Distrito Federal formó el procedimiento administrativo de responsabilidad núm. QC/0011/FEB-94, mediante el que se determinó que el señor Sotero Galván Gutiérrez, agente de la Policía Judicial del Distrito Federal, era administrativamente responsable por la detención arbitraria, incomunicación y tortura en contra de Alfonso Martín del Campo Dodd. Este procedimiento administrativo, sin embargo, no tuvo ninguna injerencia en el juicio; sería hasta 1999 cuando el interesado ofrecería esta resolución como prueba en un primer reconocimiento de inocencia.

Volviendo a la determinación de la segunda instancia, el sentenciado promovió un juicio de amparo directo contra la misma, que fue resuelto por el Cuarto Tribunal Colegiado en Materia Penal del Primer Circuito, el 2 de diciembre de 1997, en el sentido de negar el amparo ${ }^{6}$. Esta determinación fue recurrida por el quejoso ante la Primera Sala de la SCJN, la cual desechó por improcedente el recurso, el 9 de febrero de 1998, al considerar que no existía planteamiento de constitucionalidad.

Tendrían que transcurrir trece años ${ }^{7}$ para que el caso volviera a la SCJN. La vía fue un segundo incidente de reconocimiento de inocencia (el RI-5/2010) que fue resuelto por la Séptima Sala Penal del Tribunal Superior de Justicia del Distrito Federal, el 25 de octubre de 2011, en sentido igualmente desfavorable para Alfonso Martín del Campo ${ }^{8}$. Esta resolución fue utilizada como acto reclamado de un juicio de amparo (expediente 1183/2011), que fue resuelto por el juez Sexto de Distrito de Amparo en Materia Penal en el Distrito Federal, el 30 de abril de 2013, en el sentido de conceder el amparo, por falta de motivación, para el efecto de que se volviera a dictar el reconocimiento de inocencia ${ }^{9}$.

A pesar de ese resultado, tanto el quejoso (en un recurso principal y otro adhesivo) como el Ministerio Público impugnaron la sentencia. El Cuarto Tribunal Colegiado en Materia Penal del Primer Circuito integró el expediente 109/2013, para resolver todos los recursos; pero sería la Primera Sala de la SCJN quien terminaría haciéndolo vía el ejercicio de la facultad de atracción (SEFA-189/2013), mediante la intercesión del ministro Arturo Zaldívar Lelo de Larrea.

Como adelanté, la Primera Sala de la SCJN resolvió el caso en la sesión celebrada el 18 de marzo de 2015 mediante una sentencia que concedió el amparo y, por ende, la

${ }^{4}$ La sentencia fue dictada por el Juzgado Quincuagésimo Quinto Penal en el Distrito Federal en la causa penal 57/1992.

5 El recurso de apelación interpuesto por el sentenciado, lo resolvió la Octava Sala Penal del Tribunal Superior de Justicia del Distrito Federal.

${ }^{6}$ Se trata del juicio de amparo directo núm. 2004/97-475.

7 El caso siguió durante todo ese tiempo otros caminos derivados, precisamente, de la forma en la que Martín del Campo había sido condenado: litigio internacional ante el sistema interamericano, recomendaciones de organismos de derechos humanos, intervenciones procedentes del ámbito legislativo, entre otras.

${ }_{8}$ Anteriormente, Alfonso Martín del Campo había intentado un primer reconocimiento de inocencia: el RI-1/99, resuelto por la Décima Séptima Sala Penal del Tribunal Superior de Justicia del Distrito Federal, el 29 de abril de 1999 en forma adversa, aun cuando había presentado como prueba la mencionada resolución del procedimiento administrativo de responsabilidad núm. QC/0011/FEB-94, en el que se determinó que el policía judicial Sotero Galván Gutiérrez era administrativamente responsable por la detención arbitraria, incomunicación y tortura del señor Martín del Campo.

9 Cuaderno del juicio de amparo 1183/2011, páginas de la 971 a la 991. 
libertad inmediata del quejoso. En engrose se cerró hasta el 9 de febrero de 2016 y se publicó al día siguiente, casi once meses después.

A continuación se presentan dos esquemas: el primero contiene las principales etapas procesales por las que atravesó el caso (figura 1). En la primera columna se nombra la etapa correspondiente, en la segunda su contenido y en la tercera una línea de tiempo con el nombre de la autoridad que emitió el acto. El segundo esquema (figura 2) representa las etapas procesales posteriores al cierre del procedimiento ordinario y al correspondiente juicio de amparo, con las mismas variables: nombre, contenido, línea de tiempo y autoridades. El propósito de dividir en dos grandes partes el esquema es mostrar que lo que sucedió en la segunda parte del proceso es lo que se relaciona con las fuentes del Derecho Internacional de los Derechos Humanos y que, por tanto, la Corte habría podido resolver el caso, sencillamente, atendiendo al reconocimiento de inocencia sin necesidad de complicar más la resolución.

\section{Figura 1}

Hechos:

Investigación:

Causa penal:

Segunda instancia:

Primer juicio de amparo:

Recurso de revisión:
Hechos violentos en el domicilio, huida y captura del presunto responsable.

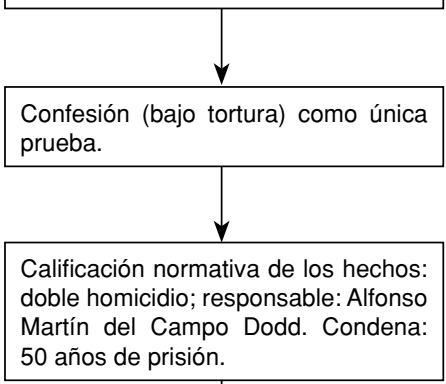

50 años de prisión.

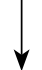

Recurso de apelación: confirmación de la sentencia de primera instancia: se afirma que la confesión es la única prueba en la que se basa la condena.

Primer juicio de amparo directo: se revisa la constitucionalidad de la sentencia de segunda instancia, y se niega el amparo.

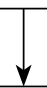

Se revisa la procedencia y se determina que el recurso no procede porque no existe un planteamiento de constitucionalidad.

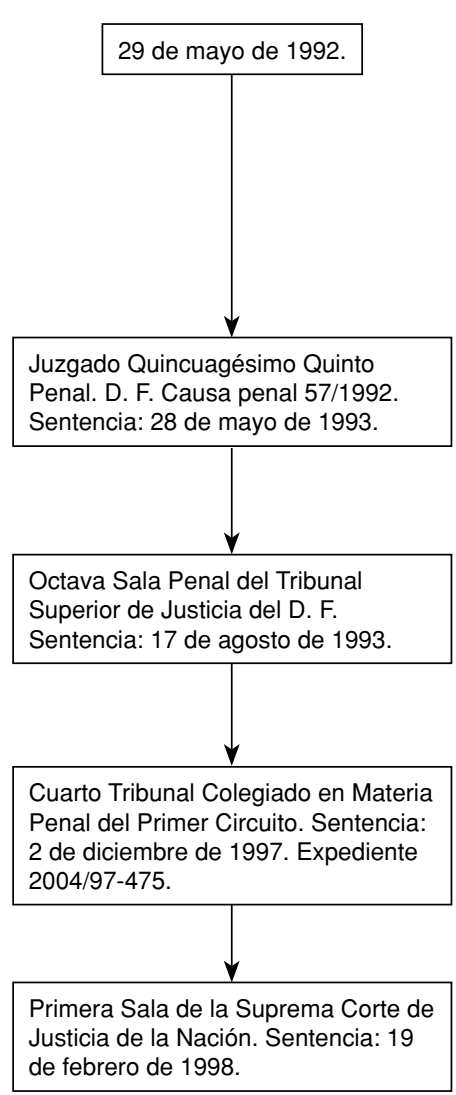


Figura 2

Primer incidente de reconocimiento de inocencia:

Juicio de amparo:

Recurso

de Revisión:

Facultad

de atracción

Decisión-acto

Decisión-documento (engrose):
Se presentó como prueba el expediente QC/0011/FEB.94, por la cual se determinó que el señor Sotero Galván Gutiérrez, agente de la entonces Policía Judicial del Distrito Federal, era administrativamente responsable por la detención arbitraria, incomunicación y tortura en su contra.

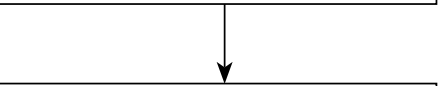

Se niega el reconocimiento de inocencia.
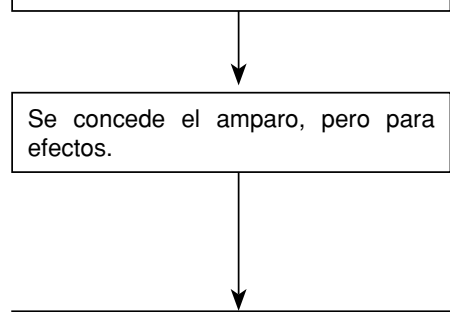

Se admite el recurso, pero no es resuelto por el Tribunal Colegiado.

Se determina atraer el recurso.

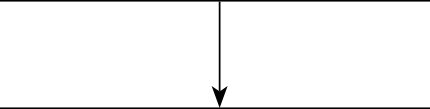

Se decide no tomar en cuenta los informes de la $\mathrm{CIDH}$; se concede el amparo; y se ordena la libertad inmediata del reo.

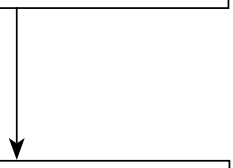

Se hace un análisis conjunto de la causa penal y los reconocimientos de inocencia; se mencionan las pruebas contenidas en los informes de la $\mathrm{CIDH}$; y no se hace pronunciamiento alguno sobre su obligatoriedad.
RI-1/99. Décima Séptima Sala Penal el TSJDF. 29 de abril de 1999.

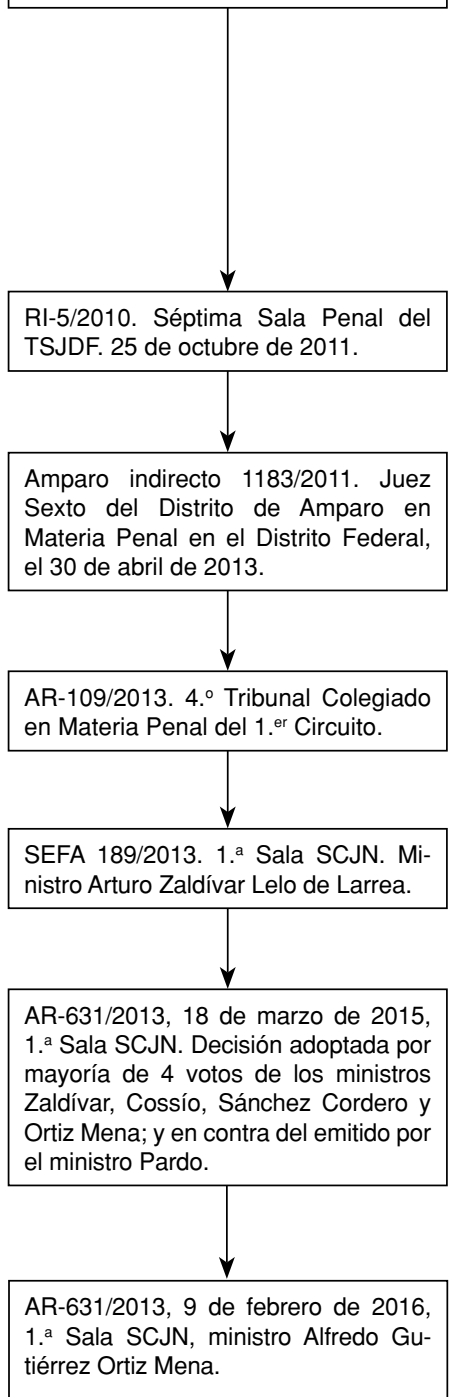




\section{DECISIÓN ACTO Y DECISIÓN DOCUMENTO}

\subsection{La decisión-acto}

En este caso — como en muchos otros- primero se toma la decisión colegiada y posteriormente se busca su justificación mediante un proceso de argumentación que satisfaga, en primer lugar, a quienes la tomaron y, en segundo lugar, al resto del mundo. Así, es posible distinguir entre la decisión-acto y la decisión-documento. La primera constituye un acuerdo (algunas veces de tipo político), donde la retórica y la dialéctica determinan el resultado, mientras que la segunda es un proceso de justificación en el que la lógica deductiva juega un papel fundamental, aunque no decisivo. Sin embargo, ambas acciones se encuentran estrechamente vinculadas porque la primera determina la segunda, lo cual no tiene nada de particular. El problema viene cuando la decisión del caso implica la evasión de una cuestión políticamente controvertida - como el no pronunciarse por la obligatoriedad de un informe de la CIDH - que constituye uno de los cuestionamientos centrales de una de las partes. Cuando esto sucede, la elaboración de la sentencia suele ser más difícil, porque se hace necesario maquillar esa omisión mediante procesos argumentativos dirigidos a justificar o validar la omisión. Una vez que emitido el engrose es posible develar el maquillaje porque el proceso argumentativo deja entrever algunas huellas de la omisión.

¿Qué y cómo se decidió el caso en la Primera Sala? Como ya señalé, la primera discusión se llevó a cabo el 2 de julio de 2014, a partir de un proyecto de resolución presentado por el Ministro José Ramón Cossío Díaz, en el que se proponía conceder el amparo liso y llano, tomando en cuenta el valor probatorio y normativo de los Informes 33/09 y 117/09 de la CIDH. La propuesta se traducía en la libertad inmediata de Alfonso Martín del Campo y agotaba completamente todos los temas planteados en el recurso. Ese día, sin embargo, no solo se desechó el proyecto de resolución, sino que también se tomó conciencia de la envergadura del problema, y se plantearon los extremos y los riesgos del mismo. Se trataba de un verdadero dilema: o se daba algún tipo de valor a los informes de la CIDH o se buscaban pruebas de la tortura en el expediente. En el primer caso, se presentaba la «desventaja» de dar valor a los Informes de fondo de la Comisión, lo que supondría que en casos futuros tendría que otorgárseles ese mismo valor; en el segundo caso, es decir, si se buscaban pruebas de la tortura, la Corte se enfrentaba ante el problema de no encontrar pruebas «fehacientes» de la misma ${ }^{10}$, tal y como se había concluido ya por la primera y segunda instancia y por los tribunales de amparo cuando resolvieron el doble homicidio. Pero los ministros ya no estaban frente al caso de homicidio, sino frente a un incidente de reconocimiento de inocencia; más concretamente,

10 Hasta ese momento, el único medio de prueba de la tortura legalmente admisible habría sido una sentencia en la que se condenara a alguien por la comisión de ese delito; no fue sino hasta el 6 de noviembre de 2013, que la Primera Sala de la SCJN determinó que, para actuar en consecuencia ante una denuncia de tortura, no era necesario contar con una sentencia condenatoria. Cfr. Amparo en revisión 703/2012, 6 de noviembre de 2013. Cinco votos por la concesión del amparo de los ministros Arturo Zaldívar Lelo de Larrea, José Ramón Cossío Díaz, Alfredo Gutiérrez Ortiz Mena, Olga Sánchez Cordero de García Villegas y Jorge Mario Pardo Rebolledo. Mayoría de tres votos por el amparo liso y llano de los ministros Arturo Zaldívar Lelo de Larrea, Alfredo Gutiérrez Ortiz Mena y Olga Sánchez Cordero de García Villegas. Disidentes: José Ramón Cossío Díaz y Jorge Mario Pardo Rebolledo. Ponente: Jorge Mario Pardo Rebolledo. Encargado del engrose: Alfredo Gutiérrez Ortiz Mena. Secretario: José Alberto Mosqueda Velázquez. 
estaban frente a un amparo concedido para efectos y frente a dos recursos de revisión (uno del quejoso y otro del Ministerio Público) que, por distintas razones, cuestionaban esa concesión de amparo (el primero buscaba un amparo liso y llano, mientras que el segundo, pedía que se negara el amparo). Consecuentemente, la Corte tenía que decidirse por alguna de estas dos alternativas y hacerse cargo de las consecuencias. Los ministros se decantaron por buscar pruebas de tortura en la causa penal.

En este punto conviene preguntarnos: cla Corte iba a buscar pruebas de tortura en un caso en el que los tribunales del D. F. y de la Federación en su momento concluyeron en que Alfonso Martín del Campo era el responsable del homicidio? ¿Encontrar pruebas de tortura en donde nunca se admitió siquiera la posibilidad de consignar a los policías acusados de llevarla a cabo? ¿Pruebas de tortura ante un caso cerrado en la que la propia Corte había intervenido confirmando las determinaciones judiciales ordinarias? ¿No habría sido más fácil atenerse al expediente relativo al reconocimiento de inocencia, donde los informes de la CIDH podían ser tomados como pruebas de tortura?

Como señalé, la decisión-acto se llevó a cabo en la sesión celebrada el 18 de marzo de 2015 sin tomar en cuenta ni el proyecto del ministro Cossío ni tampoco el del ministro Pardo. No hubo, pues, un tercer proyecto. De este modo los ministros llegaron a un acuerdo por mayoría de votos, según el cual: 1) debía concederse el amparo liso y llano y, en consecuencia, ordenar la libertad inmediata de Martín del Campo; y 2) las pruebas de tortura debían recogerse no del expediente de reconocimiento de inocencia (donde estaban integrados los informes de la CIDH), sino del expediente penal.

La decisión no se basó en un proyecto escrito o en una propuesta concreta. No se fueron revisadas líneas de argumentación en positivo, sino que la decisión se tomó a partir del conocimiento de un hecho por todos asumido: el quejoso había sido torturado. Con o sin informes de la CIDH, la mayoría de los ministros asumieron una postura política. La argumentación necesaria para justificarla llegaría once meses después y no podría variar el resultado: Martín del Campo estaba fuera de la cárcel.

Ahora bien: ¿cómo quedó la decisión-documento? ¿Se ajustó al acuerdo tomado en la decisión-acto? El expediente era por todos conocido, pero el engrose no. Como veremos, el engrose no respetó del todo el acuerdo tomado en la decisión-acto, pero realmente ya no importaba, porque nadie lo discutiría en serio nunca más ${ }^{11}$. ¿Qué relevancia tiene esta variación?

\subsection{La decisión-documento}

El engrose está estructurado de tal forma que no se distingue claramente entre la causa penal, los reconocimientos de inocencia y los distintos juicios de amparo; tampo-

11 Existe una normatividad interna en la Corte según la cual los engroses se circulan por cinco días hábiles a fin de que los ministros que votaron la decisión-acto verifiquen si se tomaron en cuenta o no sus opiniones. La mayoría de las veces no se revisan los engroses, con lo cual es posible «colar» argumentos, datos o pruebas que no estaban en el acuerdo inicial. Alguna vez algún ministro protestó con relación a la variación de los engroses. Ocurrió el 28 de agosto 2008, al resolverse las acciones de inconstitucionalidad 146/2008 y 147/2008. La protesta no tuvo repercusión alguna. La suerte ya estaba echada. Esto muestra que las variaciones entre la decisiónacto y la decisión documento dan cuenta de un problema de no poca importancia en la toma de decisiones. 
co deja fuera algunas pruebas contenidas en los informes de la CIDH, contrariamente a lo acordado en la decisión-acto. Lo que más llama la atención, sin embargo, es que no existe un adecuado planteamiento de la cuestión a resolver en el recurso de revisión al que obedeció, sino que el caso se resuelve mezclando las distintas cuestiones surgidas en las diferentes etapas procesales.

Así, se empieza haciendo un recuento sobre los distintos y recientes avances jurisprudenciales en materia de tortura, especialmente a partir del caso Arzate ${ }^{12}$, a finales del 2013. Enseguida, se aclara que, a lo largo de la secuela procesal, las autoridades tuvieron la noticia de los hechos de tortura, y que omitieron los deberes constitucionales y de orden internacional de investigar los hechos denunciados, no solo como delito, sino también como violación de los derechos humanos. Posteriormente, se traza la distinción de la tortura como hecho delictivo y como práctica violatoria de derechos humanos, y se hace hincapié en que la prohibición de la tortura constituye un derecho absoluto que pertenece al dominio del ius cogens. Asimismo, se precisa cuáles son los deberes del Estado que generan ese reconocimiento, tales como la obligación de investigar cuando exista evidencia razonable y otros matices relacionados con el tema.

En otro punto del engrose la Sala se plantea que lo que debe resolverse es si se acredita o no el supuesto del art. 614, fracción VI, del Código de Procedimientos Penales para el Distrito Federal. Para ello, sin embargo, opta por analizar, no las pruebas del expediente del reconocimiento de inocencia, sino las contenidas en la causa penal del homicidio. El resultado de este análisis es que Alfonso Martín del Campo fue detenido arbitrariamente, retenido y torturado y, en consecuencia, se violaron sus derechos de libertad personal; además, que no fue puesto a disposición del Ministerio Público de forma inmediata y que no se acreditó la flagrancia. A partir de ello, la Sala concluye que todas las pruebas derivadas de tales violaciones - solo existía la confesión mediante tortura - resultan inválidas, por ser violatorias de la Constitución, de la Convención Americana sobre Derechos Humanos, así como de la Convención Interamericana para Prevenir y Sancionar la Tortura.

En seguida, se concluye que la Séptima Sala Penal del Tribunal Superior de Justicia del Distrito Federal —autoridad responsable en el amparo relativo al reconocimiento de inocencia - no debió excluir las pruebas ofrecidas por el quejoso, entre otras, los informes de la $\mathrm{CIDH}$, que habían sido excluidos en la decisión-acto y que, de conformidad con el acuerdo político al que habían llegado los ministros, no debían ser tomadas en cuenta. La Sala concluye que no existen dudas de que Alfonso Martín del Campo fue torturado ${ }^{13}$.

Finalmente, la Sala regresa a contrastar esta última valoración con las pruebas de cargo del doble homicidio, y concluye que ninguna de ellas acredita genuinamente la participación del quejoso en esos hechos, esto es, se concluye que Martín del Campo no cometió el doble homicidio que se le imputó.

Así, luego de todo este serpenteo argumental, la Sala concluye dos cosas: a) que, debido que se acreditó la tortura, quedó desvanecida la única prueba en la que se

${ }_{12}$ Cfr. Amparo en revisión 703/2012.

13 Ibid., párrafos 205, 206 y 207 de la sentencia. 
sustentó la condena de homicidio: la confesión; y b) que debe declararse fundado el incidente de reconocimiento de inocencia.

Con todo, el engrose es omiso en cuanto a la pregunta acerca de la obligatoriedad de los informes de la CIDH. No responde en modo alguno la cuestión, sino que se esfuerza por acreditar la tortura apenas mencionando los referidos informes como pruebas, pero sin señalar con alguna precisión qué papel jugaron en el razonamiento judicial.

\subsection{Lo que dicen estas variaciones}

¿Qué supone el hecho de variar una decisión-acto a la hora de redactar la decisióndocumento? A mi juicio, una falta de seriedad y una suerte de preferencia por las decisiones-acto. Dado que las variaciones no suelen ser radicales, pareciera que los ministros de la Corte las consienten, porque, por un lado, no tienen mucho tiempo para controlarlas y, por otro, los costos no son graves. Sin embargo, las variaciones demuestran que pesa más la deliberación que el documento que, se supone, las refleja. Si uno piensa en que la deliberación se lleva a cabo mediante el cumplimiento de ciertas reglas y pautas propias de la argumentación oral en los cuerpos colegiados, entonces el resultado debe ser respetado. Para ello, debería vigilarse muy de cerca el engrose, para que fuera un fiel reflejo de los acuerdos derivados del ejercicio de la deliberación racional; sin embargo, en la Corte mexicana no siempre se hace.

En lo personal, considero que este es un signo de politización de la Corte que supone un alejamiento de los argumentos por escrito, lo cual no es un asunto menor, si se piensa en que la decisión-documento será utilizada en el futuro a manera de precedente. La distorsión acaba afectando a la propia Corte cuando los ministros se dan cuenta de que el precedente que se cita no se ajusta a lo que ellos votaron en la decisión-acto. La célebre CT-293/2011 es un caso que ejemplifica esta situación, ya que cuando el engrose estuvo listo, nadie o casi nadie estaba dispuesto a admitir los términos del engrose.

La forma de resolver esta situación es la emisión de votos particulares y concurrentes que suelen acompañar a las ya de por sí voluminosas sentencias, con lo cual se complica todavía más la imagen (al menos escrita) de la Corte mexicana. Los documentos resultantes acaban siendo ininteligibles; lo cual obedece, muchas veces, a la dificultad de ensamblar cada una de las posiciones de los ministros o magistrados; ingrata tarea que corresponde a los sufridos letrados.

En suma, las variaciones, profundas o superficiales, que se dan entre las decisiones-acto y las decisiones-documento dicen mucho de la Corte Suprema. Hablan de un sistema de decisión que: no es eficiente (se invierte una gran cantidad de energía entre el proyecto inicial y la elaboración del engrose); no es transparente; no es fiel con las posiciones genuinas de los ministros y no permite que los justiciables y el público en general tengan claro cual es la postura genuina de la Corte en un determinado tema. 


\section{LAS RAZONES DE UN OLVIDO: SOBRE LA EVASIÓN DE LA CUESTIÓN}

¿Por qué la mayoría de los ministros integrantes de la Primera Sala de la SCJN prefirieron no pronunciarse (ni en la decisión-acto ni en la decisión-documento), sobre la obligatoriedad el Informe 117/09 de la CIDH? Bien pudieron argumentar que no es vinculante por no ser una sentencia internacional, o que no es una fuente formal del Derecho, o que la Corte no es la destinataria de ese tipo de informes. Sin embargo, optaron por el silencio. En la decisión-documento se hace mención de los informes de forma un tanto subrepticia.

Como sea, la resolución (acto y documento) es incompleta porque, al no responder si los informes de la CIDH son o no obligatorios, el quejoso, en primer lugar, y la comunidad jurídica, en segundo, se quedan esperando la respuesta de la Corte y, con ello, una buena cantidad de implicaciones relevantes, tales como la importancia del trabajo de la CIDH, la utilidad del compromiso internacional del Estado mexicano con relación a la Comisión, las respuestas dadas por México al interactuar con ese órgano y, en general, el valor mismo del Derecho internacional de los derechos humanos.

Entiendo que cualquier respuesta conlleva riesgos: si se opta por un sí (los Informes sí son obligatorios), entonces en el futuro cualquier Informe de la Comisión — que es un organismo cuasi-jurisdiccional— que mandatara al Poder Judicial de la Federación alterar el curso de un juicio, tendría que ser acatado con el consecuente menoscabo de la autonomía; si se opta por un no (los Informes no son obligatorios), entonces podría decirse que esas investigaciones que no terminan en la Corte de Costa Rica son papel mojado. Como sea, la pregunta no puede ser evadida sin un razonamiento, tal como se presenta en el engrose. Incluso la vía del no pronunciamiento demandaba la expresión de razones: el silencio no es una razón.

¿Cuáles son las razones de fondo? Una primera razón que encuentro es el formalismo jurídico, porque si se hubiera tratado de una sentencia de la CorteIDH no habría habido ningún problema. Es decir, pienso que la Corte supo que lo que decía el Informe, con respecto a la tortura, era cierto desde la decisión-acto, pero no podía atenderse por ser un simple informe. Sin embargo, en el engrose, la Sala parece olvidarse de esta formalidad y lo toma en cuenta aunque de forma casi residual en un obiter dicta. En estas condiciones no puede decirse que el informe haya sido realmente integrado al engrose, con lo cual la Primera Sala evadió la cuestión planteada con un costo apenas perceptible para el caso concreto, pero no así para casos futuros. En efecto, para el caso concreto, esta omisión no representó mayores problemas porque, con todo, se concedió el amparo y Alfonso Martín del Campo Dodd fue liberado, pero para otros casos la pregunta acerca de la relevancia de los pronunciamientos de la CIDH sigue en el aire.

Una segunda razón es de tipo político: hay resquemor por atender los pronunciamientos de la CIDH, quizás porque se trata de un órgano más político que jurídico con una vocación de denuncia y señalamiento de las violaciones a los derechos humanos, y a ningún Estado le gusta que le digan que sus instituciones violan derechos o que sus acciones dirigidas a prevenir o reparar esas violaciones son insuficientes. La SCJN, como parte del Estado, prefiere resolver estas cuestiones de forma doméstica, aunque ello suponga no responder a alguna de las cuestiones planteadas en el juicio de amparo. 
Este comportamiento evasivo no es aislado. Existe una marcada resistencia de la SCJN para hacerse cargo en serio del llamado nuevo paradigma ${ }^{14}$. En efecto, el caso Martín del Campo se olvidará pronto gracias a una sentencia esencialmente satisfactoria, pero al mismo tiempo se suma a otros casos relevantes relacionados con esa falta de apertura: las contradicciones de tesis 21/2011, 293/2011 (en las que se estableció que el parámetro de regularidad constitucional se compone por los derechos humanos contenidos en la Constitución y en los tratados internacionales, aunque con prevalencia de las restricciones a los derechos contenidas en el texto constitucional); y el expediente varios 1396/2011 «Inés y Valentina» (en el que se reiteró el criterio de la CT 293 en el sentido de que las restricciones a los derechos deben prevalecer incluso en contra de una sentencia internacional que condene al Estado mexicano). En todos estos casos, la Corte mexicana no ha estado a la altura de los mandatos de la reforma Constitucional de junio de 2011, porque la interpretación del texto constitucional y el cumplimiento de las sentencias de la CorteIDH han dejado mucho que desear.

El mensaje que la Corte envía con este tipo de decisiones es que las normas, pronunciamientos y resoluciones en materia de derechos humanos a cargo de organismos internacionales no tienen la fuerza obligatoria que dicen tener, porque no pueden incidir decisivamente en los casos resueltos por los tribunales nacionales. Consecuentemente, la eliminación de prácticas deleznables como la tortura y, en general, la lucha por los derechos humanos son anhelos de los que parece estar celoso el Poder Judicial de la Federación. En efecto, cuando instancias internacionales actúan en ejercicio de sus competencias y se pronuncian sobre violaciones a los derechos humanos, las respuestas de nuestra Corte no son del todo receptivas, quizás porque ve la esfera de los derechos humanos como un territorio en disputa. La sociedad mexicana es, sin duda, la gran perdedora en este jaloneo.

\section{EL INFORME 117/09 DE LA CIDH COMO INGREDIENTE DE LA DECISIÓN}

Como se ha visto, nunca se despejaron las dudas sobre si el Informe 117/09 de la CIDH resultaba o no vinculante para el Estado mexicano y, por ende, si podía ser considerado para integrarlo en el razonamiento judicial. A mi juicio, habría sido adecuado

14 La expresión «nuevo paradigma» suele aplicarse al cambio de perspectiva surgido en México, a partir de las reformas constitucionales y legales en materia de Derechos Humanos y juicio de amparo de 2011 y 2013, pero especialmente a partir de la interpretación que la Suprema Corte de Justicia de la Nación llevó a cabo al respecto, al resolver el expediente varios 912/2010 (cumplimiento de la sentencia de la CorteIDH en el Caso Rosendo Radilla Pacheco), el 12 de julio de 2011. Como se sabe, a partir de esos cambios, se entiende que todas las autoridades del país, dentro del ámbito de sus competencias, tienen la obligación de velar no solo por los derechos humanos contenidos en la Constitución Federal, sino también por aquellos contenidos en los instrumentos internacionales celebrados por el Estado mexicano, adoptando la interpretación más favorable al derecho humano de que se trate, lo que se conoce en la doctrina como principio pro persona. Estos mandatos - dijo el Tribunal Pleno_- deben interpretarse junto con lo establecido en el art. 133 constitucional; así, se obtiene que, aun cuando existieren disposiciones en contrario, los jueces están obligados a preferir los derechos humanos contenidos en la Constitución y en los tratados internacionales; consecuentemente, dejarán de aplicar esas normas inferiores dando preferencia a las contenidas en la Constitución y en los tratados en la materia. Cfr. R. Lara Chagoyán, Argumentación jurídica. Estudios prácticos, 2. ${ }^{a}$ ed., México, Porrúa, 2015, 57-59. 
responder esta cuestión distinguiendo entre obligatoriedad del instrumento y utilidad de su contenido, como a continuación mostraré.

\subsection{Respondiendo el planteamiento del quejoso}

Como se sabe, la obligación de cumplir lo dispuesto en las resoluciones emitidas por órganos internacionales en materia de derechos humanos corresponde a un principio básico del derecho sobre la responsabilidad internacional del Estado, respaldado por la jurisprudencia internacional, llamado pacta sunt servanda, según el cual los Estados deben cumplir el tratado internacional de buena fe ${ }^{15}$. Al respecto, el art. 26 de la Convención de Viena sobre el Derecho de los Tratados de 1969, ratificada por México el 5 de julio de 1974, por el presidente Luis Echeverría Álvarez ${ }^{16}$, establece que: «[t] odo tratado en vigor obliga a las partes y debe ser cumplido por ellas de buena fe». Por otra parte, el art. 27 del mismo tratado establece que los Estados no pueden «invocar las disposiciones de su derecho interno como justificación del incumplimiento de un tratado». Así, las obligaciones de los Estados parte vinculan a todos los poderes y órganos del Estado, los cuales tienen el deber de cumplir de buena fe con el derecho internacional ${ }^{17}$.

En específico, en relación con el Sistema Interamericano de Derechos Humanos, de conformidad con el art. 2 de la Convención Americana sobre Derechos Humanos, los Estados tienen la obligación de «adoptar, con arreglo a sus procedimientos constitucionales y a las disposiciones de (dicha) Convención, las medidas legislativas o de otro carácter que fueren necesarias para hacer efectivos (los) derechos y libertades» reconocidos en dicho tratado. Ello podría implicar, dependiendo de la situación concreta, dos cosas: i) la supresión de las normas y prácticas de cualquier naturaleza que signifiquen una violación a la Convención, o ii) la expedición de normas y el desarrollo de prácticas conducentes a la efectiva observancia de dicho instrumento ${ }^{18}$.

15 Cfr. Responsabilidad internacional por expedición y aplicación de leyes violatorias de la Convención (arts. 1 y 2 de la Convención Americana sobre Derechos Humanos). Opinión Consultiva OC-14/94 de 9 de diciembre de 1994. Serie A No. 14, párr. 35, y Caso Barrios Altos vs. Perú. Supervisión de cumplimiento de Sentencia. Resolución de la CorteIDH de 7 de septiembre de 2012, considerando cuarto. Lo anterior ha sido recogido en «Resolución aprobada por la Asamblea General [sobre la base del Informe de la Sexta Comisión (A/56/589 y Corr.1)] 56/83, Responsabilidad del Estado por hechos internacionalmente ilícitos, 85. ${ }^{a}$ sesión plenaria, de 12 de diciembre de 2001, Documentos Oficiales de la Asamblea General, quincuagésimo sexto periodo de sesiones, Suplemento No. 10 y correcciones (A/56/10 y Corr.1 y 2). Corte IDH. Resolución de cumplimiento de sentencia de 20 de marzo de 2013 en el caso Gelman vs. Uruguay, párr. 59».

16 Conviene tener presente que la Cámara de Senadores aprobó la Convención de Viena el 29 de diciembre de 1972, y fue publicada en el Diario Oficial de la Federación el 14 de febrero de 1975.

${ }_{17} \mathrm{Cfr}$. Corte IDH. Resolución de cumplimiento de sentencia de 20 de marzo de 2013 en el caso Gelman vs. Uruguay, párr. 59. Caso Castillo Petruzzi y otros vs. Perú. Supervisión de Cumplimiento de Sentencia. Resolución de la CorteIDH de 17 de noviembre de 1999, considerando cuarto, y Caso Barrios Altos vs. Perú. Supervisión de cumplimiento de Sentencia. Resolución de la CorteIDH de 7 de septiembre de 2012, considerando cuarto.

${ }_{18}$ Cfr. Corte IDH. Resolución de cumplimiento de sentencia de 20 de marzo de 2013 en el caso Gelman vs. Uruguay, párr. 60. Caso Almonacid Arellano y otros vs. Chile. Excepciones Preliminares, Fondo, Reparaciones y Costas. Sentencia de 26 de septiembre de 2006. Serie C No. 154, párr. 118; Caso Ximenes Lopes vs. Brasil.Fondo, Reparaciones y Costas. Sentencia de 4 de julio de 2006. Serie C No. 149, párr. 83, y Caso «La Última Tentación de Cristo» (Olmedo Bustos y otros). Sentencia de 5 de febrero de 2001. Serie C No. 73, párr. 85. La Corte ha 
Con base en lo anterior, podemos concluir que los Estados deben garantizar tanto el cumplimiento de lo que se han obligado al ratificar los diferentes tratados en materia de derechos humanos, como su efecto útil en el plano de sus respectivos derechos internos. Es importante destacar que este principio se aplica tanto a las normas sustantivas de los tratados de derechos humanos (las que contienen disposiciones sobre los derechos reconocidos), como a las normas procesales ${ }^{19}$.

Conviene precisar que en el sistema interamericano de derechos humanos existen diferencias conceptuales entre las sentencias emitidas por tribunales internacionales (vgr. Corte IDH $)^{20}$ y las decisiones - informes, resoluciones y opiniones- emitidas por otros órganos internacionales de derechos humanos, cuya naturaleza puede variar entre sí (vgr. $\mathrm{CIDH}^{21}$, el Comité de Derechos Humanos de Naciones Unidas ${ }^{22}$, los diferentes Grupos de Trabajo de la ONU) ${ }^{23}$.

afirmado en relación con ello que, [e]n el derecho de gentes, una norma consuetudinaria prescribe que un Estado que ha celebrado un convenio internacional, debe introducir en su derecho interno las modificaciones necesarias para asegurar la ejecución de las obligaciones asumidas. Esta norma aparece como válida universalmente y ha sido calificada por la jurisprudencia como un principio evidente («príncipe allant de soi»; Echange des populations grecques et turques, avis consultatif, 1925, C.P.J.I., série B, no. 10, p. 20). Cfr. Caso Almonacid Arellano y otros vs. Chile, párr. 117; Caso «Instituto de Reeducación del Menor» vs. Paraguay. Excepciones Preliminares, Fondo, Reparaciones y Costas. Sentencia de 2 de septiembre de 2004. Serie C No. 112, párr. 205, y Caso Bulacio Vs. Argentina. Fondo, Reparaciones y Costas. Sentencia de 18 de septiembre de 2003. Serie C No. 100, párr. 140.

19 Cfr. Corte IDH. Resolución de cumplimiento de sentencia de 20 de marzo de 2013 en el caso Gelman vs. Uruguay, párr. 63. Caso Ivcher Bronstein vs. Perú. Competencia. Sentencia de 24 de septiembre de 1999. Serie C No. 54, párr. 37, y Caso Barrios Altos vs. Perú. Supervisión de cumplimiento de Sentencia. Resolución de la CorteIDH de 7 de septiembre de 2012, considerando quinto.

${ }^{20}$ De conformidad con lo establecido en el art. 67 de la Convención Americana, «[e]l fallo de la Corte será definitivo e inapelable», el cual produce los efectos de autoridad de cosa juzgada. Asimismo, el art. 68.1 de la Convención Americana estipula que «[1] os Estados Partes en la Convención se comprometen a cumplir la decisión de la Corte en todo caso en que sean partes». En el mismo sentido, la SCJN, al resolver el expediente Varios 912/2010, estableció que «las resoluciones pronunciadas por (la Corte Interamericana) son obligatorias para todos los órganos del Estado mexicano al haber figurado como parte en un litigio concreto». Vid. la Tesis Aislada P. LXV/2011 (9. ${ }^{a}$.

${ }^{21} \mathrm{El}$ art. 50 de la Convención Americana sobre Derechos Humanos establece:

1. De no llegarse a una solución, y dentro del plazo que fije el Estatuto de la Comisión, esta redactará un Informe en el que expondrá los hechos y sus conclusiones. Si el Informe no representa, en todo o en parte, la opinión unánime de los miembros de la Comisión, cualquiera de ellos podrá agregar a dicho Informe su opinión por separado. También se agregarán al Informe las exposiciones verbales o escritas que hayan hecho los interesados en virtud del inciso 1.e. del art. 48.

2. El Informe será transmitido a los Estados interesados, quienes no estarán facultados para publicarlo.

3. Al transmitir el Informe, la Comisión puede formular las proposiciones y recomendaciones que juzgue adecuadas.

El art. 51, por su parte, establece lo siguiente:

1. Si en el plazo de tres meses, a partir de la remisión a los Estados interesados del Informe de la Comisión, el asunto no ha sido solucionado o sometido a la decisión de la Corte por la Comisión o por el Estado interesado, aceptando su competencia, la Comisión podrá emitir, por mayoría absoluta de votos de sus miembros, su opinión y conclusiones sobre la cuestión sometida a su consideración.

2. La Comisión hará las recomendaciones pertinentes y fijará un plazo dentro del cual el Estado debe tomar las medidas que le competan para remediar la situación examinada.

3. Transcurrido el periodo fijado, la Comisión decidirá, por la mayoría absoluta de votos de sus miembros, si el Estado ha tomado o no medidas adecuadas y si publica o no su Informe.

${ }^{22}$ De conformidad con el Pacto de Derechos Civiles y Políticos, el Comité de Derechos Humanos podrá presentar Informes sobre los Estados Parte. Vid. art. 28 y ss.

${ }^{23}$ Existen tres tipos: a) grupos de trabajo; $b$ ) grupo de trabajo especial; c) grupos de trabajo especial de composición abierta; y d) grupos de trabajo de composición abierta, vid. bttp://www.un.org/es/ga/about/ subsidiary/other.shtml. 
No obstante lo anterior, es claro que existe la obligación internacional de cumplir de buena fe con los tratados (pacta sunt servanda) y que, si bien no todos los instrumentos obligan de la misma forma o con la misma intensidad, ello no implica que aquellos que no son sentencias no tengan ningún valor.

Lo anterior nos lleva a afirmar que unos y otros instrumentos obligan de manera distinta o en distinto grado. Para poder distinguir entre uno y otro tipo de obligaciones, me voy a permitir introducir, de manera estipulativa, la distinción entre «deber» y «obligación». Al respecto, Juan Carlos Bayón ha señalado que estos términos se han usado la mayoría de las veces como equivalentes, pero que hay quienes han encontrado una diferencia notable entre ellos. Sucintamente, viene a decir que por «deber» habría que entender la modalidad o posición normativa más elemental, es decir, una conducta calificada deónticamente como no opcional; «tener un deber» es, simplemente, ser destinatario de una norma de ese tipo. Por «obligación», en cambio, se podría entender alguna clase de modalidad o posición normativa compleja que podría estar determinada por la conexión entre una norma N1 que prescribe una conducta a un agente A1 y otra norma N2 que prescribe a cierto órgano aplicar una sanción a A1 si transgrede N1, de manera que una obligación implicaría la combinación de dos «deberes». Otra manera de entender a la obligación jurídica es verla como «una posición normativa compleja integrada, según los casos, por diferentes combinaciones de «deberes» $\mathrm{y}$ - suponiendo que no sean a su vez reductibles a «deberes»— situaciones de poder normativo - y correlativa sujeción-o ausencia del mismo ${ }^{24}$.

Pues bien, podemos convenir en que las sentencias internacionales son obligatorias en el sentido apuntado, mientras que las decisiones - Informes, resoluciones y opiniones- son debidas, es decir, no opcionales. La consecuencia de cada una de ellas es distinta: en el primer caso, el Estado mexicano es responsable del incumplimiento y podría ser sancionado internacionalmente por ello; mientras que en el segundo caso, la consecuencia sería simbólica - incluso política - y podría suponer un desprestigio internacional.

Con el objeto de hacer más sencillo el uso de la distinción, podemos convenir en que las sentencias son obligatorias en sentido estricto, mientras que las decisiones son obligaciones en sentido amplio. De este modo, podemos concluir que el Informe 117/09 es obligatorio en sentido amplio, lo cual implica que el Estado mexicano, en este caso la SCJN, no puede obviar su existencia, sino que debe tomarlo en cuenta, debe usarlo en algún sentido que resulte justificado.

\section{2. ¿Qué utilidad tiene el Informe 117/09 de la CIDH?}

La autoridad responsable del amparo, el Juez de Distrito y también la Primera Sala de la SCJN fueron conscientes, cada uno en su momento, de que la única prueba por la que se había condenado a Alfonso Martín del Campo era la confesión, porque así lo había reconocido el Tribunal de apelación de la causa penal — la Octava Sala del

${ }^{24}$ Cfr. J. C. BAYÓN, «Deber Jurídico», en Enciclopedia Iberoamericana de Filosofía. El Derecho y la Justicia, edición de E. GARZÓN VALDÉS y F. LAPORTA, Madrid, Trotta, 1996, 325. 
Tribunal Superior de Justicia del Distrito Federal— en el expediente toca 454/93, de 17 de agosto de 1993, en cuya página 29 se afirma:

La declaración confesoria aludida, rendida por el ahora procesado, resulta ser el único indicio de prueba relevante en cuanto al esclarecimiento de los derechos que nos ocupa, pues el precitado inculpado es el único que establece un panorama respecto a la forma en que acaecieron los hechos.

Sin embargo, lo que no resultaba claro era que la confesión hubiera sido obtenida mediante actos de tortura, porque, desde el punto de vista jurídico, la tortura no estaba probada ni en la causa penal, ni el primer juicio de amparo, ni en el primer reconocimiento de inocencia. Por ello, resultaba imprescindible acreditar la tortura en el reconocimiento de inocencia. Pues bien, el Informe 117/09 de la CIDH habría valido para este propósito. Veamos.

A lo largo de las discusiones de este caso, nunca quedó clara cuál era la relevancia de determinar la obligatoriedad del Informe 117/09 de la CIDH. El Informe está dirigido al Estado mexicano a través de una serie de recomendaciones que se traducen en el impulso de una serie de medidas orientadas a la anulación de la confesión de Alfonso Martín del Campo, así como de todas las pruebas derivadas de la misma; a la revisión de todo el proceso judicial; a su liberación inmediata; a la investigación de los hechos de tortura y sanción de los responsables; y a la reparación de las violaciones ${ }^{25}$.

Siendo así las cosas, ni la autoridad responsable, ni el juez de Distrito, ni la Primera Sala de la SCJN eran destinatarias de esas recomendaciones; por ello, ninguna de ellas podría haber ordenado, por ejemplo, la liberación de Alfonso Martín del Campo.

Lo anterior es así, porque el reconocimiento de inocencia no es un mecanismo para atender las indicaciones del Informe de fondo, ya que ninguna de las autoridades mencionadas resultaba competente para ello. Por ello, resulta extraño que el juez de Distrito, en una clara desviación de la cuestión, resolviera el juicio de amparo como si se le hubiere preguntado por la soberanía del Estado o por las especificaciones técnicas de un informe de la CIDH frente a una sentencia de la CorteIDH.

El Informe 117/09 debió haberse tomado en cuenta como una prueba, tal como lo ofreció Alfonso Martín del Campo, y que arroja información sobre hechos que no fueron controvertidos por el Estado mexicano, es decir, que este los da por ciertos y que además cuentan con un respaldo probatorio e institucional que así lo demuestra. En efecto, las conclusiones del Informe 117/09 son las siguientes:

\section{CONCLUSIONES}

126. Con base en las consideraciones de hecho y de derecho que anteceden, la Comisión Interamericana ratifica su conclusión respecto a que Alfonso Martín del Campo Dodd fue detenido arbitrariamente el 30 de mayo de 1992 y sometido a torturas y otros tratos crueles, inhumanos y degradantes por policías judiciales de la Ciudad de México, con el objeto de hacerle confesar el homicidio de su hermana Juana Patricia Martín del Campo Dodd, y su cuñado Gerardo Zamudio Aldaba, cometido la noche anterior.

127. Igualmente, la CIDH reitera que no se respetaron las garantías del debido proceso de Alfonso Martín del Campo Dodd, en particular el derecho a la presunción de

25 Cfr. Informe 117/09 de la CIDH, párrafos del 129 al 132. 
inocencia, en virtud del valor otorgado por distintos magistrados a su supuesta confesión obtenida bajo tortura. Tampoco se garantizó a la víctima en el presente caso la protección de sus derechos fundamentales.

128. Asimismo, reitera que los hechos establecidos en el presente informe constituyen violaciones de los artículos 5, 7, 8(1), 8(2), 8(3) y 25 de la Convención Americana, así como de los artículos 6, 8, y 10 de la Convención Interamericana para Prevenir y Sancionar la Tortura; todo ello en violación al deber de respeto y garantía consagrado en el artículo 1(1) de la Convención Americana.

Por lo anterior, si al resolver el recurso de revisión en el juicio de amparo, la Primera Sala de la SCJN hubiera atendido la cuestión efectivamente planteada, entonces habría tenido que rectificar la valoración del juez de Distrito señalando que el Informe 117/09 de la CIDH resultaba obligatorio en el sentido de «no opcional» (supra $\$ 4.1$ ) y, en consecuencia, habría podido valorar de primera mano las afirmaciones sobre los hechos de tortura ahí contenidas, sin necesidad de haber complicado tanto las cosas.

\section{A MANERA DE CONCLUSIÓN}

La Corte mexicana, como cualquier tribunal de máxima instancia, resuelve conflictos mediante una decisión basada en argumentos. La forma de decidir, sin embargo, es peculiar en el caso mexicano porque el acto de decisión no siempre se corresponde con el documento (engrose) que contiene las razones de la decisión. Esta variación es relevante porque impacta al funcionamiento de la Corte y a su legitimidad de cara a la sociedad. He buscado exponer esta situación mediante el análisis de un caso controvertido: Martín del Campo, en el que uno de los temas centrales era pronunciarse sobre la obligatoriedad de los informes de la CIDH. En la decisión-acto se excluyen, pero en la decisión-documento no queda clara la exclusión. Con todo, en ninguna de las dos decisiones se responde realmente un planteamiento central: la obligatoriedad de dichos informes.

A mi juicio, era perfectamente posible hacerse cargo del tema de la obligatoriedad, mediante una adecuada integración de algunos materiales probatorios provenientes del Derecho Internacional de los derechos humanos al razonamiento judicial. De este modo, la solución del caso habría sido mucho más simple: se habría podido declarar fundado el recurso de revisión del quejoso y, por ende, se habría podido convertir la concesión del amparo «para efectos» en una concesión «lisa y llana».

Sin duda, la deliberada evasión de la cuestión relativa a la obligatoriedad el Informe 117/09 de la CIDH es una cuestión preocupante. Pareciera como si un fantasma vagara por el edificio de Pino Suárez núm. 2, del Centro Histórico de la Ciudad de México (locación del edificio sede de la SCJN) y dejase cierto influjo formalista entre sus muros. Este influjo parece tener un efecto de rechazo hacia los pronunciamientos de la CIDH, quizás por no ser un órgano plenamente jurisdiccional, aunque lo que diga sea cierto. Formalismo y política se funden en ese rechazo. Es una lástima que lo que se rechace sean denuncias y señalamientos de violaciones a los derechos humanos.

El presente caso se suma a otros en los que se nota una suerte de resistencia de la SCJN para hacerse cargo del nuevo paradigma. Se trata, al menos, de las contradiccio- 
nes de tesis 21/2011, 293/2011 (en las que se estableció que el parámetro de regularidad constitucional se compone por los derechos humanos contenidos en la Constitución y en los tratados internacionales, aunque con prevalencia de las restricciones a los derechos contenidas en el texto constitucional); y el expediente varios 1396/2011 «Inés y Valentina» (en el que se reiteró el criterio de la CT 293 en el sentido de que las restricciones a los derechos deben prevalecer incluso en contra de una sentencia internacional que condene al Estado mexicano). Esta colección de casos muestra que la Corte no parece ir en la dirección marcada por el Constituyente en la reforma Constitucional de junio de 2011, porque la interpretación llevada a cabo por la Corte no ha estado a la altura de esos mandatos, ya que se ha inclinado la balanza hacia los valores de la autoridad y de la ley, que a los derechos humanos y los límites al ejercicio del poder. Por ello, parece que vale más una restricción al ejercicio de un derecho humano que el derecho humano mismo.

Nuestra Corte no parece apreciar y aceptar libremente las normas, pronunciamientos y resoluciones en materia de derechos humanos a cargo de organismos internacionales. No se trata de que los «acepte sin más», sino de que sepa abrir el razonamiento judicial para incorporar racionalmente algunos contenidos provenientes del Derecho internacional. Sin embrago, con sus últimas resoluciones, la Corte parece estar celosa de ese territorio en disputa que constituyen las violaciones a los derechos humanos. Pareciera que quisiera resolverlos sin ayuda del exterior, sin la colaboración de instancias que parece considerar de dudosa autoridad, como el Sistema Interamericano de Derechos Humanos. Mientras eso sucede, las prácticas deleznables como la tortura y, en general, las violaciones a los derechos humanos no disminuyen, sino que aumentan de manera preocupante. Ante este panorama desolador, ¿será correcta una actitud anti-aperturista?

En suma, con este trabajo he buscado mostrar que el proceso argumentativo de una sentencia es tan importante como el producto del mismo. Por ello, la selección de las estrategias metodológicas para abordar un caso como este no es cosa menor. Pensando en ello, he tratado de hacer una evaluación tanto del proceso decisorio como del engrose elaborado. El balance final nos habla de una buena decisión en general, aunque accidentada y complicada en su proceso y con una cuestión no resuelta: la obligatoriedad de los informes de la CIDH. 